Tersedia Online di http://journal2.um.ac.id/index.php/jmsp/

ISSN Online : 2541-4429

\title{
ANALISIS JABATAN PENJAGA SEKOLAH DASAR NEGERI
}

\author{
Sagita Manggala Dewi \\ E-mail: sagitamanggaladewi@gmail.com \\ SDN Kayukebek
}

\begin{abstract}
This study aims to find out the job specifications, job descriptions, duration of working time, and salary of public elementary school guard in Pasuruan regency. This research uses a quantitativ approach with descriptive design. The result of this study indicate that school guard has 5 kinds of job specifications, namely gender, age, rank/class, duration of work, and last education. Description of the work of school guard outside the main tasks there are 26 additional tasks. The duration of the school guard's time is 8 hours/days and the salary obtained is $<$ Rp. $500.000-\geq$ Rp. 2.500.000.
\end{abstract}

Keywords: job analysis, school guard

\begin{abstract}
Abstrak: Penelitian ini bertujuan untuk mengetahui spesifikasi jabatan, deskripsi kerja, durasi waktu kerja, dan gaji penjaga sekolah dasar negeri di Kabupaten Pasuruan. Penelitian ini menggunakan pendekatan kuantitatif dengan rancangan deskriptif. Hasil dari penelitian ini menunjukkan bahwa penjaga sekolah memiliki 5 macam spesifikasi jabatan yaitu jenis kelamin, usia, pangkat/golongan, masa kerja dan pendidikan terakhir. Deskripsi kerja penjaga sekolah di luar tugas pokok ada 26 tugas tambahan. Durasi waktu kerja penjaga sekolah adalah 8 jam per hari dan gaji yang diperoleh adalah $<$ Rp.500.000 - $\geq$ Rp. 2.500.000.
\end{abstract}

Kata kunci: analisis jabatan, penjaga sekolah.

Analisis jabatan yang dilakukan dengan teliti, akan menghasilkan data informasi yang akurat, kemudian dapat dijadikan sumber data untuk mengelola sumber daya manusia. Peraturan Badan Kepegawaian Negara Nomor 12 Tahun 2011 disebutkan, bahwa analisis jabatan adalah "proses pengumpulan, pendataan, pengolahan dan penyusunan data jabatan menjadi informasi jabatan". Lembaga yang juga mengelola sumber daya manusia adalah lembaga pendidikan/ sekolah. Berdirinya gedung sekolah, maka pengelola sekolah membutuhkan seorang tenaga kependidikan bagian petugas layanan khusus yaitu penjaga sekolah.

Sesuai Permendiknas Nomor 24 Tahun 2008, setiap sekolah wajib mempunyai penjaga sekolah. Adanya penjaga sekolah yang memenuhi standar kompetensi yang sesuai dengan Peraturan Menteri Pendidikan Nasional, diyakini keamanan berjalan dengan baik. Namun, pada kenyataannya penjaga sekolah yang dimiliki belum memenuhi standar kompetensi yang ada, tersebut dikarenakan, penjaga sekolah diangkat dengan sukarelawan.
Permendiknas Nomor 24 Tahun 2008 sudah disebutkan bahwa penjaga sekolah harus berpendidikan minimal SMP. Penjaga sekolah bertugas menjaga keamanan sekolah dan lingkungan agar tercipta suasana aman, tertib, nyaman, dan berwibawa. Jika penjaga sekolah telah melaksanakan tugas dan kewajibannya dengan baik, maka sudah menjadi keharusan sekolah untuk memberikan balikan atas pekerjaan.

Berdasarkan apa yang ditemui di lapangan, uraian tugas penjaga sekolah kurang jelas, setiap penjaga sekolah memiliki perbedaan jenis pekerjaan ditiap sekolah, terutama sekolah negeri. Penjaga sekolah juga seringkali melakukan tugas dinas yang bukan menjadi tanggung jawabnya. Sekolah seharusnya menerapkan peraturan yang adabahwa penjagamemilikitugas dinasyangharus dikerjakan. Bukan menyuruh juga mengerjakan tugas lain tetapi tidak ada penambahan gaji yang sesuai. Penelitian ini bertujuan untuk mengetahui spesifikasi jabatan, deskripsi kerja, durasi waktu kerja, dan gaji penjaga sekolah dasar negeri di Kabupaten Pasuruan. 


\section{METODE}

Penelitian ini menggunakan penelitian kuantitatif, yaitu "penelitian yang menggunakan data bersifat kuantitatif untuk kepentingan analisisnya sehingga dalam proses pengumpulan data dilakukan pengukuran (measurement) atau bisa menggunakan data kuantitatif yang telah tersedia (non-metrik)" (Setyadin, 2005:12). Penelitian ini menggunakan rancangan penelitian deskriptif. Penelitian deskriptif menurut Wiyono (2007:08) merupakan penelitian yang bertujuan "untuk mendeskripsikan suatu fenomena sebagaimana adanya pada waktu penelitian dilakukan".

Jumlah populasi sebanyak 716 penjaga sekolah dan jumlah sampel sebanyak 105. Pengambilan sampel menggunakan teknik purposive sampling. Pengambilan sampel dengan menggunakan teknik purposive sampling yaitu dengan mengambil sampel didasarkan pada ciriciri tertentu yang dianggap memiliki kesamaan dengan populasi yang sudah ditentukan.

Teknik pengumpulan data menggunakan angket atau kuesioner. Pada penelitian ini angket yang digunakan merupakan angket tertutup dan terbuka dikarenakan peneliti ingin memberikan kesempatan yang luas untuk responden kesempatan yang luas untuk responden dalam menjawab pertanyaan dan agar peneliti juga dapat membawa responden untuk menjawab sesuai dengan tujuan penelitian. Angket penelitian sebelum digunakan harus melalui dua analisis uji instrumen, yaitu uji validitas dan uji reliabilitas instrumen. Data yang diperoleh langsung dari penyebaran kuesioner kepada penjaga sekolah dasar negeri di Kabupaten Pasuruan.

Teknik analisis data dalam penelitian ini menggunakan teknik analisis deskriptif. Teknik analisis deskriptif digunakan untuk menganalisis data dengan cara "mengambarkan atau mendeskripsikan data yang telah terkumpul sebagaimana adanya bermaksud membuat kesimpulan berlaku untuk umum atau generalisasi” (Sugiyono, 2010:207).

\section{HASIL}

Jenis kelamin penjaga sekolah berjumlah 105 orang atau $100 \%$ yaitu laki-laki, berusia $25-35$ tahun sebanyak 25 orang $(23,80 \%), 36-45$ tahun sebanyak 37 orang $(35,20 \%), 46-55$ tahun sebanyak 23 orang
(21,90\%), 56-65 tahun sebanyak 19 orang $(18,10 \%)$, dan 66-75 tahun sebanyak 1 orang $(1,00 \%)$. Golongan pangkat III/a berjumlah 9 orang $(8,60 \%), \mathrm{II} / \mathrm{d}$ berjumlah 11 orang $(10,50 \%)$, II/c berjumlah 15 orang $(14,30 \%)$, II/b berjumlah 7 orang $(6,70 \%)$, II/a berjumlah 13 orang $(12,40 \%), \mathrm{I} / \mathrm{d}$ berjumlah 5 orang $(4,80 \%), \mathrm{I} / \mathrm{c}$ berjumlah 7 orang $(6,70 \%)$, dan Pegawai Tidak Tetap (PTT) atau honorer atau sukwan berjumlah 38 orang $(36,20 \%)$. Masa kerja $0-5$ tahun sebanyak 24 orang $(23,81 \% 0,6-10$ tahun sebanyak 39 orang $(37,14 \%)$, $11-15$ tahun sebanyak 33 orang $(31,42 \%), 16-20$ tahun sebanyak 4 orang $(3,80 \%)$, dan $21-25$ tahun sebanyak 5 orang $(4,76 \%)$. Pendidikan terakhir sebanyak 3 orang $(2,90 \%)$, Sekolah Menengah Pertama (SMP) 8 orang $(7,60 \%)$, Sekolah Menengah Atas (SMA) 82 orang $(78,10 \%), 3$ orang $(2,90 \%)$ berpendidikan terakhir D-II, dan S-1 sebanyak 9 orang $(8,60 \%)$.

Berdasarkan hasil analisis deskriptif melalui metode SPSS 17.00 for Windows variabel deskripsi kerja penjaga sekolah menunjukkan nilai minimum sebesar $=156$, nilai maximum sebesar $=285$, nilai mean sebesar $=229,09$. Kemudian mencari setiap kelas interval dari indikator deskripsi kerja sesuai angket yang telah disebarkan kepada 105 repsonden dengan cara mencari skor tertinggi dan skor terendah dari jumlah pernyataan dan jumlah pilihan yang ada pada angket. Secara garis besar hasil deskripsi data pada penelitian ini dapat dilihat pada Tabel 1.

Tabel 1 Deskripsi Kerja Penjaga Sekolah

\begin{tabular}{|c|c|c|}
\hline No & Deskripsi Kerja & Kategori \\
\hline 1 & Melaksanakan tugas pengamanan sekolah & $\begin{array}{l}\text { Sangat } \\
\text { tinggi }\end{array}$ \\
\hline 2 & Memonitor lingkungan sekolah sebanyak 3 (tiga) kali & Sedang \\
\hline 3 & $\begin{array}{l}\text { Mengawasi dan menjaga keamanan lahan parkir seko- } \\
\text { lah }\end{array}$ & $\begin{array}{l}\text { Sangat } \\
\text { tinggi }\end{array}$ \\
\hline 4 & $\begin{array}{l}\text { Memelihara dan menjaga barang-barang milik seko- } \\
\text { lah }\end{array}$ & $\begin{array}{l}\text { Sangat } \\
\text { tinggi }\end{array}$ \\
\hline 5 & $\begin{array}{l}\text { Bekerjama dengan dinas terkait apabila ada masalah } \\
\text { keamanan yang tidak dapat dilakukan secara internal } \\
\text { atau sudah terjadi perbuatan melanggar hukum }\end{array}$ & $\begin{array}{l}\text { Sangat } \\
\text { tinggi }\end{array}$ \\
\hline 6 & $\begin{array}{l}\text { Mengatasi hal-hal yang mengganggu keamanan dan } \\
\text { ketertiban }\end{array}$ & $\begin{array}{l}\text { Sangat } \\
\text { tinggi }\end{array}$ \\
\hline 7 & Mengamankan pelaksanaan kegiatan sekolah & $\begin{array}{l}\text { Sangat } \\
\text { tinggi }\end{array}$ \\
\hline 8 & $\begin{array}{l}\text { Menjaga ketenangan dan keamanan kompleks sekolah } \\
\text { siang dan malam }\end{array}$ & Sedang \\
\hline 9 & Merawat peralatan keamanan & Sedang \\
\hline 10 & Menjaga kebersihan pos jaga & Sedang \\
\hline 11 & Mengisi buku catatan kejadian & Tinggi \\
\hline 12 & Melaporkan kejadian secepatnya & Tinggi \\
\hline 13 & $\begin{array}{l}\text { Mengawasi keluar masuknya orang, barang, kenda- } \\
\text { raan di lingkungan sekolah }\end{array}$ & Tinggi \\
\hline
\end{tabular}


Seluruh penjaga sekolah melaksanakantugas pokok dan menjalankan fungsi dari penjaga sekolah itu sendiri. Beberapa penjaga sekolah juga memiliki tugas tambahan, hal itu bisa dilakukan setiap hari dan kondisional. Setelah melakukan penelitian, peneliti menemukan sebanyak 26 tugas tambahan penjaga sekolah dasar negeri di Kabupaten Pasuruan. Jenis tugas tambahan penjaga sekolah secara rinci dapat dilihat pada Tabel 2.
Setiap penjaga sekolah memiliki durasi kerja/jam kerja yang berbeda-beda. Hal ini menyesuaikan pula dengan kondisi sekolah. Durasi kerja/jam kerja ditentukan oleh sekolah dan dijelaskan kepada penjaga sekolah sebelum diterima bekerja. Frekuensi penjaga sekolah yang memiliki durasi kerja 6 jam sebanyak 9 orang atau sebesar $8,60 \%$. Kemudian penjaga sekolah yang memiliki durasi kerja 7 jam sebanyak 29\%

Tabel 2 Jenis Tugas Tambahan Penjaga Sekolah

\begin{tabular}{|c|c|c|c|}
\hline No & Tugas Tambahan & Frekuensi & $\%$ \\
\hline 1 & Mengantar surat ke UPT/Dinas & 45 & $42,86 \%$ \\
\hline 2 & Membuat minuman untuk guru/tamu & 29 & $27,62 \%$ \\
\hline 3 & Membeli makan & 14 & $13,33 \%$ \\
\hline 4 & Memperbaiki sarana dan prasarana & 38 & $36,19 \%$ \\
\hline 5 & Memfotocopy berkas & 32 & $30,48 \%$ \\
\hline 6 & Merapikan dan menyapu taman/kebun sekolah & 24 & $22,86 \%$ \\
\hline 7 & Mengatur dan menyiapkan keperluan rapat & 16 & $15,24 \%$ \\
\hline 8 & Memperbaiki tempat duduk & 2 & $1,90 \%$ \\
\hline 9 & $\begin{array}{l}\text { Membersihkan lingkungan sekolah (ruang kelas, kan- } \\
\text { tor guru, kamar mandi, halaman sekolah) }\end{array}$ & 56 & $53,33 \%$ \\
\hline 10 & Mengecat tembok dan pagar sekolah & 17 & $16,19 \%$ \\
\hline 11 & Membuka dan menutup pagar/pintu ruang & 33 & $31,43 \%$ \\
\hline 12 & Menyiapkan keperluan upacara bendera & 20 & $19,05 \%$ \\
\hline 13 & Menyiapkan peralatan drum band & 3 & $2,86 \%$ \\
\hline 14 & Menyiapkan keperluan senam & 4 & $3,81 \%$ \\
\hline 15 & Menyiapkan keperluan ekstra al banjari & 3 & $2,86 \%$ \\
\hline 16 & Menyiapkan keperluan ekstra tari & 2 & $1,90 \%$ \\
\hline 17 & Menyiapakan keperluan ekstra pramuka & 4 & $3,81 \%$ \\
\hline 18 & Mengantar siswa sakit pulang/lomba & 16 & $15,24 \%$ \\
\hline 19 & Membakar sampah & 7 & $6,67 \%$ \\
\hline 20 & Menyalakan lampu sekolah di sore hari & 9 & $8,57 \%$ \\
\hline 21 & Mengantar guru bila ada keperluan di luar sekolah & 5 & $4,76 \%$ \\
\hline 22 & Mengambil soal ujian di UPT & 2 & $1,90 \%$ \\
\hline 23 & Membayar pajak & 1 & $0,95 \%$ \\
\hline 24 & Membantu sebagai tenaga administrasi & 5 & $4,76 \%$ \\
\hline 25 & Memperbaiki saluran air & 25 & $23,81 \%$ \\
\hline 26 & Membeli ATK sekolah & 18 & $17,14 \%$ \\
\hline
\end{tabular}


atau sebesar $27,60 \%$. Selanjutnya, penjaga sekolah yang memiliki durasi kerja 8 jam sebanyak $41 \%$ atau sebesar $39,00 \%$. Penjaga sekolah yang memiliki durasi kerja 9 jam sebanyak 3 orang atau sebesar $1,90 \%$. Kemudian penjaga sekolah yang memiliki durasi kerja 12 jam sebanyak 5 orang atau sebesar $4,80 \%$. Selanjutnya penjaga sekolah yang memiliki durasi kerja 15 jam sebanyak 17 orang atau sebesar $16,20 \%$. Penjaga sekolah yang memiliki durasi kerja 18 jam sebanyak 1 orang atau sebesar $1,00 \%$.

Standar honorarium penjaga sekolah yang berstatus Pegawai Negeri Sipul (PNS) didasari oleh pangkat golongan yang dimilikinya yang sudah diatur oleh pemerintah. Sedang penjaga sekolah yang berstatus sebagai Pegawai Tidak Tetap (PTT)/Honorer/Sukwan memperoleh honor sesuai ketentuan sekolah. Hasil penelitian dapat dilihat pada Tabel 3.

Tabel 3 Besar Honorarium/Gaji Penjaga Sekolah per Bulan

\begin{tabular}{cccc}
\hline \multicolumn{4}{c}{ Besar Gaji Per Bulan } \\
\hline Kategori & F & $\%$ & $\begin{array}{c}\text { Jabatan Struk- } \\
\text { tural }\end{array}$ \\
\hline$<$ Rp. 500.000 & 27 & $25,70 \%$ & PTT \\
$\begin{array}{c}\text { Rp. 500.000-Rp. } \\
1.000 .000\end{array}$ & 10 & $9,50 \%$ & PTT, PNS I/c \\
$\begin{array}{c}\text { Rp. 1.000.000- } \\
\text { Rp. 1.500.000 }\end{array}$ & 1 & $1,00 \%$ & PNS II/a \\
$\begin{array}{c}\text { Rp. 1.500.000- } \\
\text { Rp. 2.000.000 }\end{array}$ & 14 & $13,30 \%$ & $\begin{array}{c}\text { PNS I/c, I/d, } \\
\text { dan II/a }\end{array}$ \\
$\begin{array}{c}\text { Rp. 2.000.000- } \\
\text { Rp. 2.500.000 }\end{array}$ & 46 & $43,80 \%$ & $\begin{array}{c}\text { II/a, II/c, dan } \\
\text { II/d }\end{array}$ \\
$\geq$ Rp. 2.500.000 & & & $\begin{array}{c}\text { PNS I/d, II/a, } \\
\text { II/b, II/c, II/d, } \\
\text { dan III/a }\end{array}$ \\
\hline Total & 105 & $100 \%$ & \\
\hline
\end{tabular}

\section{PEMBAHASAN}

Spesifikasi jabatan penjaga sekolah yaitu usia, pendidikan, dan jenis kelamin. Dalam melaksanakan tugas seorang penjaga sekolah, jenis kelamin yang memadai adalah pria. Hal ini dikarenakan pria lebih mampun menjalankan tugas pokok sebagai penjaga sekolah. Selain itu, ada beberapa resiko yang menjadikan jabatan ini tidak bisa diisi oleh wanita. Sesuai dengan hasil penelitian yang ada, dengan jumlah sampel 105 orang, semua berjenis kelamin pria. Pada tamatan jenjang pendidikan, sebanyak 102 orang yang sudah mampu memenuhi syarat untuk spesifikasi jabatan penjaga sekolah. Dari 105 orang, diketahui bahwa 102 orang berpendidikan terakhir yaitu di atas SMP, sedangkan 3 orang lainnya berpendidikan terakhir SD. Pada spesifikasi jabatan penjaga sekolah sudah ditentukan oleh Peraturan Menteri Pendidikan Nasional Republik Indonesia Nomor 24 Tahun 2008 pada ayat 1 tercantum bahwa penjaga sekolah berpendidikan minimal SMP/MTS atau sederajat. Sehingga dapat disimpulkan bahwa penjaga SDN di Kabupaten Pasuruan sudah banyak yang memenuhi spesifikasi jabatan sesuai dengan peraturan tersebut. Akan tetapi, beberapa sekolah ada yang penjaga sekolah yang lulusan jenjang pendidikan yang tidak sesuai dengan peraturan yang ada.

Selanjutnya pada rentang usia yang dimiliki penjaga sekolah, penjaga sekolah seharusnya memiliki rentang usia sekitar 25-55 tahun. Sebab pekerjaan yang dilaksanakan oleh penjaga sekolah membutuhkan tenaga yang lebih. Tidak hanya itu, resiko dari jabatan ini juga sangat tinggi. Usia menjadikan patokan penjaga sekolah dalam bekerja, pada umumnya penjaga sekolah yang sudah berusia 56-75 tahun, dalam melaksanakan pekerjaan tidak secepat seperti yang usia muda. Hal ini dikarenakan, semakin tua umur seseorang maka semakin menurun juga daya kerja maupun daya berpikirnya. Pada penelitian ini mengungkap bahwa sangat banyak penjaga sekolah yang berusia 36-45 tahun. Sedangkan ada 1 orang penjaga sekolah yang berusia 66-75 tahun. Hal ini menyatakan bahwa penjaga sekolah yang berusia 36-45 tahun sangat banyak dengan jumlah 37 orang. Pada jabatan penjaga sekolah ini dalam mengemban tugasnya dibutuhkan penjaga sekolah dengan usia 25-45 tahun.

Masa kerja sebagai penjaga sekolah, hal tersebut harus sangat diperhatikan. Idealnya penjaga sekolah memiliki masa kerja 0-15 tahun. Sebab hal ini mempengaruhi hasil kerja dari penjaga sekolah. Penjaga sekolah yang sudah lama mengemban tugas tersebut, akan dapat memahami ketentuan tugas yang harus dikerjakan.

Penjaga sekolah memiliki tugas pokok yang dijabarkan menjadi 5 pernyataan, yaitu (1) memonitoring lingkungan sekolah sebanyak 
3 kali, (2) mengawasi keluar masuknya orang, barang, kendaraan, di lingkungan sekolah, (3) melaksanakan tugas pengamanan sekolah, (4) melaporkan keadaan lingkungan sekolah kepada kepala sekolah dan bekerja sama dengan dinas terkait, (5) memelihara dan menjaga barangbarang milik sekolah. Setiap pegawai memiliki tugas pokok dan fungsi masing-masing yang berbeda semua disesuaikan dengan kondisi sekolah. Penjaga sekolah tidak hanya mengerjakan tugas pokok saja, tetapi juga mengerjakan tugas tambahan yang bukan merupakan kewajibannya. Setiap penjaga memiliki tugas tambahan yang berbeda, hal itu ditentukan oleh masing-masing sekolah. Tugas tambahan tersebut dilakukan ada yang setiap hari, setiap minggu, dan setiap bulan, hal itu tergantung dari sekolahnya. Tugas tambahan yang paling banyak dilakukan oleh penjaga sekolah adalah membersihkan lingkungan sekolah (ruang kelas, kantor guru, kamar mandi, halaman sekolah), hampir 53\% penjaga sekolah melakukan hal itu.

Selanjutnya ada tugas yang dilakukan oleh $43 \%$ penjaga sekolah yaitu mengantar surat ke UPT/dinas. Kemudian tugas tambahan yang sering dilakukan penjaga sekolah adalah memperbaiki sarpas dan bangunan sekolah sebesar 36\% penjaga sekolah yang melakukan. Adapun tugas lainnya yang banyak dilakukan penjaga sekolah yaitu, memfotocopy berkas sekolah, membuka dan menutup pintu pagar/ ruang kelas, merapikan dan menyapu taman/ kebun sekolah, dan memperbaiki saluran air. Tugas tambahan tersebut tidak sesuai dengan Peraturan Menteri Pendidikan Nasional Republik Indonesia Nomor 24 tahun 2008 tentang standar Tenaga Administrasi Sekolah/Madrasah pasal 1 Ayat 3 menetapkan beberapa standar kompetensi teknis yang harus dimiliki penjaga sekolah, yaitu: (1) menguasai kondisi keamanan sekolah/ madrasah, (2) menguasai teknik pengamanan sekolah/madrasah, (3) menerapkan prosedur operasi standar pengamanan sekolah/madrasah. Selain itu juga, menurut Hendramoko (2013) tugas pokok dan fungsi penjaga sekolah adalah (1) mengatasi hal-hal yang mengganggu keamanan dan ketertiban, (2) mengamankan pelaksanaan kegiatan sekolah, (3) menjaga ketenangan dan keamanan kompleks sekolah siang dan malam, (4) Mengisi buku catatan kejadian, (5) melaporkan kejadian secepatnya,
(6) mengawasi keluar masuknya orang, barang, kendaraan di lingkungan sekolah, (7) merawat peralatan keamanan, (8) menjaga kebersihan pos jaga.

Berdasarkan pernyataan tersebut dapat diambil kesimpulan, bahwa deskripsi kerja penjaga sekolah bukan hanya yang disebutkan dalam tupoksi penjaga sekolah, masih ada beberapa tugas yang bukian merupakan tupoksi penjaga sekolah yang harus dikerjakan. Pekerjaan tersebut bahkan tidak sesuai dengan peraturan yang ada. Tugas tambahan merupakan kebijakan dari pihak sekolah yang sudah ditentukan. Jika dilihat dari standar kompetensi penjaga sekolah, maka tugas tambahan tersebut tidak dibenarkan dikarenakan hal tersebut tidak sesuai. Penjaga sekolah harus memiliki kompetensi terkait dengan pengamanan lingkungan sekolah dan menerapkan prosedur pengaman sekolah tersebut. Penjaga sekolah direkrut harus memenuhi kompetensi sebagai penjaga sekolah.

Setiap pegawai memiliki durasi jam kerja yang telah ditentukan sekolah, hal tersebut sudah dijelaskan sebelum menerima pegawai tersebut bekerja disitu. Sehingga durasi jam kerja setiap pegawai sangat berbeda. Pada umumnya durasi kerja pegawai adal 8 jam per harinya. Tetapi pada penelitian ini mengungkap bahwa masih ada penjaga sekolah yang bekerja melebihi dari 8 jam setiap harinya. Pada Peraturan Pemerintah Republik Indonesia Nomor 53 Tahun 2010 tentang Disiplin Pegawai Negeri Sipil (PNS) bahwa, "PNS wajib untuk masuk kerja dan menaati ketentuan jam kerja". Sehingga dapat diketahu bahwa PNS harus datang maupun pulang tepat waktu dan apabila berhalangan untuk hadir ke sekolah, diharuskan memberitahu pihak yang berwenang. Durasi jam kerja akan mempengaruhi waktu istirahat dan gaji yang diperoleh. Pada kenyataannya penjaga sekolah yang bekerja di atas 8 jam per harinya masih ada yang mendapat gaji < Rp. 500.000. Hal ini tidak sesuai dengan peraturan kerja seharusnya.

Standar honorarium setiap pegawai dapat ditentukan dari pihak sekolah maupun dari pemerintah. Apabila pegawai tersebut berstatus Pegawai Negeri Sipil (PNS) honor yang diperoleh didasari oleh pangkat/golongan yang dimilikinya yang sudah diatur oleh pemerintah. Namun bagi penjaga sekolah yang berstatus Pegawai Tidak Tetap (PTT) honor yang didapatkan diatur 
oleh pihak sekolah masing-masing, hal ini menyesuaikan dana Biaya Operasional Sekolah (BOS). Besar honor yang diperoleh penjaga sekolah yang berstatus PTT pada umumnya $<$ Rp.500.000 tetapi beberapa PTT dari sekolah yang memiliki dana BOS besar mendapatkan honor sebesar Rp. 500.000 - Rp. 1.000.000. Sedangkan penjaga sekolah yang berstatus PNS, honor yang diperoleh sebesar Rp. 1.000.0000 $\geq$ Rp. 2.500.000. Pemberian gaji kepada penjaga sekolah diberikan setiap bulan.

Menurut pendapat Darmawan (2006:525) yang mengemukakan, bahwa timework (upah menurut waktu) adalah " suatu sistem penentuan upah yang dibayar menurut lama/jangka waktu yang terpakai dalam menyelesaikan suatu pekerjaan, misalnya per hari, per jam, per minggu, per bulan, dan lain-lain". Pernyataan di atas seharusnya berlaku bagi penentuan honor penjaga sekolah untuk yang berstatus PTT agar honor yang didapatkan sesuai dengan pekerjaan yang dilakukan. Jadi dapat disimpulkan bahwa penjaga sekolah yang berstatus PNS menerima honor berdasarkan pangkat/golongan yang dimiliki, sedangkan bagi penjaga sekolah yang berstatus PTT mendapatkan gaji berdasarkan ketentuan dari pihak sekolah masing-masing.

Untuk perbaikan mutu sumber daya manusia di sekolah, dapat melalui pelaksanaan manajemen berbasis sekolah. Di Indonesia, prinsip kemandirian, keadilan, keterbukaan, kemitraan, partisipatif, efisiensi, dan akuntabilitas menjadi palang pintu keberhasilan, pelaksanaan manajemen berbasis sekolah. Semestinya terjadi peningkatan kemandirian sekolah melalui pemberian kewenangan yang lebih besar dalam mengelola sumberdaya sekolah dan mendorong keikutsertaan semua kelompok kepentingan sebagai implikasi dan respon terhadap pelaksanaan manajemen berbasis sekolah. Seperti yang diungkapkan Triwiyanto, Kusumaningrum, dan Juharyanto (2017:67) bahwa responsibilitas manajemen berbasis sekolah tampak pada balikan yang tercermin dalam bentuk tindakan dan perilaku warga sekolah dalam hal otonomi manajemen pendidikan pada satuan pendidikan, yang dalam hal ini kepala sekolah dan guru dibantu oleh komite sekolah dalam mengelola kegiatan pendidikan.

\section{KESIMPULAN DAN SARAN}

\section{Kesimpulan}

Spesifikasi jabatan penjaga sekolah terdiri dari jenis kelamin, usia, pangkat/golongan, masa kerja dan pendidikan terakhir. Jenis kelamin penjaga sekolah semuanya laki-laki. Deskripsi kerja penjaga sekolah di luar tugas pokok dan fungsi, ada 26 tugas tambahan. Durasi jam kerja penjaga sekolah ialah 8 jam per hari, namun ada beberapa penjaga sekolah yang melaksanakan lebih dari ketentuan pemerintah. Standar honorarium pegawai yang berstatus Pegawai Negeri Sipil (PNS) honor yang diperoleh didasari oleh pangkat/golongan yang dimilikinya yang sudah diatur oleh pemerintah. Namun bagi penjaga sekolah yang berstatus Pegawai Tidak Tetap (PTT) honor yang didapatkan diatur oleh pihak sekolah masing-masing, hal ini menyesuaikan dana Biaya Operasional Sekolah (BOS).

\section{Saran}

Kepala Dinas Pendidikan Kabupaten Pasuruan, sebaiknya memberikan penjelasan atau mengadakan pertemuan untuk pembahasan tentang tupoksi masing-masing jabatan yang ada di lembaga sekolah. Seminar tersebut bisa ditujukan kepada kepala sekolah, agar sekolah dapat memahami perbedaan tugas dari penjaga sekolah, petugas kebersihan dan pesuruh sekolah. Sehingga tidak semua pekerjaan serabutan di sekolah dilakukan oleh penjaga sekolah. Sebab diketahui dari hasil penelitian bahwa penjaga sekolah memiliki 26 macam tugas tambahan yang harus dilakukan. Di samping itu, seharusnya dinas memastikan bahwa setiap sekolah memiliki penjaga sekolah agar lingkungan sekolah selalu terhindar dari tindak kriminal. Dari hasil penelitian diketahui, ada 10 sekolah yang belum memiliki penjaga sekolah. Dari hasil penelitian dapat diketahui bahwa PTT mendapatkan honor < Rp. 500.000 per bulan. Dengan adanya ketentuan batas minimal honor, setidaknya tingkat kesejahteraan penjaga sekolah yang berstatus PTT dapat naik dan berbanding lurus dengan tugas yang dikerjakan oleh penjaga sekolah. Kemudian, sebaiknya penjaga sekolah yang berstatus PTT dan sudah lama bekerja disekolah agar dipertimbangkan untuk dinaikkan status kepegawaiannya menjadi 
PNS. Untuk kepala sekolah dasar negeri di Kabupaten Pasuruan, hal pertama sebaiknya menentukan Standard Operating Procedure (SOP) untuk setiap pekerjaan yang dilakukan penjaga sekolah. Kedua, mengusulkan kenaikan pangkat untuk penjaga sekolah yang masih berstatus PTT kepada Dinas Pendidikan dan apabila belum mempunyai penjaga sekolah, seharusnya mengusulkan pengangkatan penjaga sekolah ke Dinas Pendidikan. Diketahui bahwa 10 sekolah belum mempunyai penjaga sekolah dan 38 penjaga sekolah masih berstatus PTT. Ketiga, sebaiknya tidak memberikan tugas tambahan diluar tugas pokok dari penjaga sekolah tanpa pemberian honor tambahan pula. Karena penjaga sekolah sudah memiliki tupoksi sendiri yang harus dipenuhi dan dilaksanakan. Hal ini mengacu pada hasil penelitian dengan adanya 26 tugas tambahan sementara beberapa tugas pokok dan penjaga sekolah ada yang belum terpenuhi.

\section{DAFTAR RUJUKAN}

Darmawan, W. 2006. Manajemen Kinerja. Jakarta: Erlangga.

Hendratmoko. Tanpa Tahun. Analisis Jabatan Tenaga Kependidikan. (Online), (https:// www.academia.eddu/4991681/analisis_jabatan_ tenaga_kependidikan), diakses 28 Januari 2016.

Peraturan Badan Kepegawaian Negara Nomor 12 tahun 2011 Tentang Pedoman Pelaksanaan Analisis Jabatan. Badan Kepegawaian Negera. (Online), (http://www.
scribd.com/mobile/doc/94266127/Perka -BKNNo-12-Tahun-2011-Ttg-Pedoman-PelaksanaanAnalisis-Jabatan.pdf), diakses 28 Januari 2016.

Peraturan Menteri Pendidikan Nasional Republik Indonesia Nomor 24 Tahun 2008 tentang Standar Tenaga Administrasi Sekolah. Kementerian Pendidikan Nasional Republik Indonesia. (Online), (http://sdm. data.kemdikbud.go.id/SNP/dokumen/

PermendiknasNo24Tahun2008.pdf), diakses 28 Januari 2016.

Peraturan Pemerintah Republik Indonesia Nomor 53 Tahun 2010 Tentang disiplin Pegawai Negeri Sipil. Presiden Republik Indonesia. (Online), (http://www.PP_NO-53_2010.pdf) . Diakses 28 Januari 2016.

Setyadin, B. 2005. Modul I: Preparasi Analisis Data Penelitian Kuantitatif. Malang: Jurusan Adminitrasi Pendidikan Fakultas Ilmu Pendidikan Universitas Negeri Malang.

Sugiyono. 2010. Metode Penelitian Pendidikan: Pendekatan Kuantatif, Kualitatif dan R\&D. Bandung: CV Alfabeta.

Triwiyanto, T, Kusumaningrum, D.E., Juharyanto. 2017. Community Participation Deficits in the Implementation of School-Based Management in Indonesia. Journal of Education and Practice. 8 (32): 67-74.

Wiyono, B B. 2007. Metodologi Penelitian (Pendekatan Kuantitatif, Kualitatif, dan Action Research) (Burhanuddin, Ed.). Malang: Fakultas Ilmu Pendidikan Universitas Negeri Malang. 